\title{
ENPP1 K121Q Functional Variant Enhances Susceptibility to Insulin Resistance and Dyslipidemia with Metabolic Syndrome in Asian Indians
}

\author{
Gurjit K. Bhatti $^{a}$ Sumanpreet Kaur ${ }^{b}$ Rajesh Vijayvergiyac Sanjay K. Bhadada ${ }^{c}$ \\ Sarabjit S. Mastana ${ }^{\text {e Bhupinder Singh }}{ }^{a, f}$ Jasvinder S. Bhatti ${ }^{9}$ \\ ${ }^{a}$ UGC Centre of Excellence in Applications of Nanoapplications, Panjab University, Chandigarh, India; ${ }^{\mathrm{b}}$ Department of \\ Microbial Biotechnology, Panjab University, Chandigarh, India; ' Department of Cardiology, Postgraduate Institute of \\ Medical Education and Research, Chandigarh, India; ${ }^{d}$ Department of Endocrinology, Postgraduate Institute of Medical

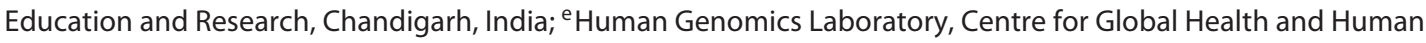 \\ Development, School of Sport, Exercise and Health Sciences, Loughborough University, Loughborough, UK; \\ fUniversity Institute of Pharmaceutical Sciences, Panjab University, Chandigarh, India; 9 Department of Biotechnology, \\ Sri Guru Gobind Singh College, Chandigarh, Chandigarh, India
}

\section{Keywords}

ENPP1 gene polymorphism · Metabolic syndrome · Obesity · Dyslipidemia · Asian Indians

\footnotetext{
Abstract

Background: Ectonucleotide pyrophosphatase/phosphodiesterase1 (ENPP1/PC-1) is a key modulator of the insulin signaling pathway, and its common variant, $\mathrm{K} 121 \mathrm{Q}$, increases the susceptibility to diabetes and cardiovascular diseases. Objectives: The main objective of the present study was to investigate the association of ENPP1 K121Q polymorphism with the pathophysiology of metabolic syndrome (MetS) in a north Indian population. Methods: A total of 567 participants (303 MetS subjects and 264 healthy controls) were examined for ENPP1 genotypes and various clinical parameters, including body mass index (BMI), waist circumference (WC), systolic and diastolic blood pressures (SBP/DBP), fasting blood glucose (FBG), cholesterol, triglycerides (TG), highdensity lipoprotein, and insulin. Genotyping was performed
}

using polymerase chain reaction-restriction fragment length polymorphism (PCR-RFLP). Statistical analysis of the data was done using SPSS. Results: Significant increases in BMI, WC, SBP, DBP, FBG, TG, low-density lipoprotein, insulin, and Homeostasis Model Assessment of insulin resistance (HOMA$\mathrm{IR}$ ) and of beta-cell function (HOMA-BF) were observed in MetS patients compared to healthy controls. Logistic regression analysis of data demonstrated a nonsignificant association of $\mathrm{QQ}$ and $\mathrm{KQ}+\mathrm{QQ}$ genotypes with increased risk of MetS (OR [95\% Cl], 1.583 [0.455-5.507], $p=0.470$ for QQ genotypes and 1.097 [0.784-1.540], $p=0.587$ for KQ+QQ genotypes). Moreover, MetS subjects carrying $Q$ alleles had significantly higher levels of TG, insulin, body fat percentage, and insulin resistance as evident by higher values of HOMAIR. Conclusions: We conclude that ENPP1 K121Q functional variant enhances susceptibility to insulin resistance and dyslipidemia in MetS subjects of an Asian Indian population.

(C) 2018 The Author(s)

Published by S. Karger AG, Basel

\begin{tabular}{ll}
\hline KARGER & $\begin{array}{l}\text { Ko 2018 The Author(s) } \\
\text { Published by S. Karger AG, Basel Oper }\end{array}$ \\
E-Mail karger@karger.com & This article is licensed under the Creative Commons Attribution- \\
www.karger.com/ijd & $\begin{array}{l}\text { NonCommercial-NoDerivatives 4.0 International License (CC BY- } \\
\text { NC-ND) (http://www.karger.com/Services/OpenAccessLicense). } \\
\text { Usage and distribution for commercial purposes as well as any dis- } \\
\text { tribution of modified material requires written permission. }\end{array}$
\end{tabular}

Dr. Jasvinder S. Bhatti

Department of Biotechnology

Sri Guru Gobind Singh College

Chandigarh 160019 (India)

E-Mail jasvinderbhatti@yahoo.com 


\section{Introduction}

Metabolic syndrome (MetS) is a cluster of metabolic abnormalities comprised of abdominal obesity, hyperinsulinemia, hypertension, and dyslipidemia. India is witnessing a depressing situation due to the escalating incidence and prevalence of MetS in rural and urban populations [1-3]. Earlier data demonstrated that about one-third of the urban population in large cities in India had MetS [4]. The increase in the prevalence of MetS leads to increased morbidity and mortality due to type 2 diabetes mellitus and cardiovascular disease in Asians [5-7]. It has been reported that the prevalence of MetS is $31.4 \%$ in an Indian population, and females $(48.2 \%)$ are more affected than their male counterparts $(16.3 \%)[3,8]$. The origins of MetS are complex and thought to involve metabolic, hormonal, genetic, and lifestyle interactions. Familial segregation analysis, twin studies, and heredity studies clearly demonstrated the genetic basis of MetS [9]. Several candidate genes for defects in insulin signaling pathways have been suggested; however, only a few studies have reported positive associations between polymorphisms of genes in the insulin signaling pathway and insulin resistance [10].

Ectoenzyme nucleotide pyrophosphate phosphodiesterase 1 (ENPP1), also known as plasma cell membrane glycoprotein 1 (PC-1), is a membrane glycoprotein that downregulates insulin signaling by interacting with the $\alpha$-subunit of the insulin receptor [11]. A common missense single nucleotide polymorphism, K121Q (rs1044498) in exon 4 of the ENPP1 gene, has a glutamine substitution for lysine at codon 121 and was found to be associated with insulin resistance [12]. No study has been reported in north Indians, except our previous study [13], so we planned to investigate the possible association of the ENPP1 K121Q polymorphism with the risk of MetS in a north Indian population.

\section{Material and Methods}

\section{Human Subjects}

We included 567 participants (303 MetS subjects and 264 healthy controls) who were the participants of our ongoing study [14]. In brief, the North Indian Diabetes and Cardiovascular Disease Research (NIDCVD) study was commenced in 2011 with the aim of investigating the interplay of genetic and environmental factors associated with diabetes and cardiovascular diseases in an Indian population. Informed written consent was obtained from all participants. All protocols were approved by the Institutional Ethics Committees of Postgraduate Institute of Medical Education and Research, Chandigarh, India. MetS was defined according to the NCEP-ATP III guidelines with an anthropometric modification of the waist circumference value that is specifically applicable to South Asians [15].
An individual was considered to have MetS when 3 or more of the following criteria were satisfied: (1) central obesity (waist circumference $\geq 90 \mathrm{~cm}$ in men and $\geq 80 \mathrm{~cm}$ in women); (2) elevated blood pressure: systolic blood pressure $\geq 130 \mathrm{~mm} \mathrm{Hg}$, diastolic blood pressure $\geq 85 \mathrm{~mm} \mathrm{Hg}$, or known treatment for hypertension; (3) elevated triglycerides (TG): fasting plasma TG $\geq 150 \mathrm{mg} / \mathrm{dL}(1.7 \mathrm{mmol} / \mathrm{L})$ or drug treatment for elevated TG; (4) reduced high-density lipoprotein cholesterol (HDL-C): fasting HDL-C $<40 \mathrm{mg} / \mathrm{dL}$ in men and $<50 \mathrm{mg} / \mathrm{dL}$ in women; and (5) hyperglycemia: elevated fasting glucose $>110 \mathrm{mg} / \mathrm{dL}$ or previously diagnosed type 2 diabetes. All patients previously diagnosed with MetS and receiving medications for hypertension, diabetes, or dyslipidemia were included in the study and were evaluated for these risk factors.

\section{Anthropometric and Clinical Characteristics}

All the anthropometric measurements were performed using standard procedures. Waist and hip circumference were measured with a nonstretchable metal tape. Height was measured with a stature meter and weight with a portable balance beam scale. Blood pressure was measured by an Omron blood pressure machine in sitting position from the left arm resting on the table, with legs uncrossed and feet flat. The quantitative measurements, such as total lipid profile (total cholesterol [TC], TG, HDL, insulin, and creatinine), were recorded from the patients' medical records if done within a maximum of 15 days before participation. Otherwise, these estimations were done in the lab using standard kits (Roche Diagnostics). Low-density lipoprotein cholesterol (LDL-C) level was calculated using the Friedewald formula, i.e., LDL-C $=\mathrm{TC}-$ [HDL-C - (TG in mg/dL/5)]. Fasting and random blood glucose levels were measured using a portable glucometer (Abbott Optium Xceed, USA). All quantitative estimations were done by following the manufacturer's instructions using a biochemistry autoanalyzer.

\section{Derived Measures}

Body mass index (BMI) was calculated using the Quetelet equation, i.e., BMI = weight in kilograms/height in meters squared. Waist to hip ratio (WHR) was calculated as the ratio of abdomen to hip circumferences. Anthropometric measurements used for the establishment of abdominal obesity were according to the cutoff values for Asian Indians. Body fat percentage (BF\%) was calculated according to the method of Lean et al. [16] using the following formulae: $\mathrm{BF} \%$ for men $=[(0.567 \times$ waist circumference in $\mathrm{cm})$ $+(0.101 \times$ age in years $)]-31.8$; and $\mathrm{BF} \%$ for women $=[(0.438 \times$ waist circumference in $\mathrm{cm})+(0.221 \times$ age in years $)]-9.4$. Homeostasis Model Assessment (HOMA) indices, such as insulin resistance (HOMA-IR) and beta-cell function (HOMA-BF), were calculated using the following formulae: HOMA-IR = [fasting insulin $(\mu \mathrm{U} / \mathrm{mL}) \times$ fasting blood glucose $(\mathrm{mmol} / \mathrm{L})] / 22.5$; and HOMA$\mathrm{BF}=[20 \times$ fasting insulin $(\mu \mathrm{U} / \mathrm{mL})] /$ fasting blood glucose $(\mathrm{mmol} / \mathrm{L})$ [17]. Abdominal obesity was defined according to the cutoffs proposed for South Asian Indians [18], i.e., WHR $>0.89$ for men and WHR $>0.81$ for women. BMI $<23$ has been proposed as low risk, BMI 23-27.5 as increased risk, and BMI $\geq 27.5$ as high risk for developing weight-related diseases in Asian populations.

\section{Amplification of ENPP1 K121Q Polymorphism}

Genomic DNA was extracted from the peripheral blood using the phenol/chloroform method. The K121Q polymorphism of ENPP1 polymorphism was detected by the polymerase chain reaction-restriction fragment length polymorphism (PCR-RFLP) meth- 
Table 1. Anthropometric and clinical measurements in the MetS and control subjects stratified by sex and disease status

\begin{tabular}{|c|c|c|c|c|c|c|c|c|c|c|c|c|}
\hline Characteristics & $n$ & mean & SD & $p$ value & $n$ & mean & SD & $p$ value & $n$ & mean & $\mathrm{SD}$ & $p$ value \\
\hline \multicolumn{13}{|l|}{ Age, years } \\
\hline Control & 113 & 57.8 & 14.7 & 0.204 & 151 & 52.4 & 13.6 & 0.000 & 264 & 54.7 & 14.3 & 0.000 \\
\hline MetS & 156 & 59.7 & 10.2 & & 147 & 58.3 & 10.6 & & 303 & 59.0 & 10.4 & \\
\hline \multicolumn{13}{|l|}{ BMI } \\
\hline MetS & 156 & 27.4 & 3.8 & & 147 & 29.8 & 4.9 & & 303 & 28.6 & 4.5 & \\
\hline \multicolumn{13}{|l|}{ WC, inch } \\
\hline Control & 113 & 36.1 & 4.4 & 0.000 & 151 & 33.7 & 4.1 & 0.000 & 264 & 34.7 & 4.3 & 0.000 \\
\hline MetS & 156 & 38.6 & 3.5 & & 147 & 37.9 & 4.3 & & 303 & 38.2 & 3.9 & \\
\hline \multicolumn{13}{|l|}{$\mathrm{HC}$, inch } \\
\hline \multicolumn{13}{|l|}{ WHR } \\
\hline Control & 113 & 0.97 & 0.07 & 0.000 & 151 & 0.9 & 0.1 & 0.000 & 264 & 0.9 & 0.1 & 0.000 \\
\hline MetS & 156 & 1.00 & 0.06 & & 147 & 0.9 & 0.1 & & 303 & 1.0 & 0.1 & \\
\hline \multicolumn{13}{|c|}{ Systolic BP, mm Hg } \\
\hline Control & 113 & 141 & 25 & 0.003 & 151 & 134 & 26 & 0.000 & 264 & 137 & 26 & 0.000 \\
\hline MetS & 156 & 149 & 21 & & 147 & 151 & 24 & & 303 & 150 & 23 & \\
\hline \multicolumn{13}{|c|}{ Diastolic BP, mm Hg } \\
\hline Control & 113 & 83 & 13 & 0.030 & 151 & 81 & 13 & 0.000 & 264 & 82 & 13 & 0.000 \\
\hline MetS & 156 & 86 & 12 & & 147 & 87 & 13 & & 303 & 87 & 12 & \\
\hline
\end{tabular}

All $p$ values $<0.05$ (two-tailed) were considered significantly different. MetS, metabolic syndrome; SD, standard deviation; BMI, body mass index; WC, waist circumference; HC, hip circumference; WHR, waist to hip ratio; BP, blood pressure.

od. The primer sequences were: F 5'GCA ATT CTG TGT TCA CTT TGG A3' and R 5'GAG CAC CTG ACC TTG ACA CA3'. The PCR was performed in a final volume of $25 \mu \mathrm{L}$, containing $20 \mathrm{ng}$ of genomic DNA, $1.5 \mathrm{mmol} / \mathrm{L} \mathrm{MgCl}, 0.2 \mathrm{mmol} / \mathrm{L}$ of each deoxynucleotide (Eppendorf, Germany), 0.5 pmol of each primer, and 1 unit of Taq DNA polymerase (New England Biolabs, USA). The initial denaturing was set up at $94^{\circ} \mathrm{C}$ for 5 min followed by 30 cycles of denaturation at $94^{\circ} \mathrm{C}$ for $50 \mathrm{~s}$, annealing at $55^{\circ} \mathrm{C}$ for $40 \mathrm{~s}$, and extension at $72^{\circ} \mathrm{C}$ for $40 \mathrm{~s}$, and the final extension was at $72^{\circ} \mathrm{C}$ for $5 \mathrm{~min}$. The amplified PCR product (208 bp) was digested with Ava II (New England Biolabs) at $37^{\circ} \mathrm{C}$ for $15 \mathrm{~h}$ with $1 \times \mathrm{NEB}$ buffer 4 in a final volume of $15 \mu \mathrm{L}$; the reaction was stopped by heat inactivation for $20 \mathrm{~min}$ at $65^{\circ} \mathrm{C}$. Results were then analyzed on $2 \%$ agarose gel.

\section{Statistical Analysis}

Results were expressed as means \pm standard deviations. $\chi^{2}$ analysis was used to test the significance of differences in frequencies. Group comparisons were done using unpaired $t$ tests. All $p$ values $<0.05$ (two-tailed) were considered as significant. Logistic regression analyses were performed to correlate various clinical parameters with disease and to calculate odds ratios (ORs) and 95\% confidence intervals (CIs) for each risk factor. Statistical analysis was performed using SPSS for Windows, version 20.

\section{Results}

Baseline Characteristics of the Study Subjects

In the present study, we assessed the interplay of K121Q polymorphism in the ENPP1 gene and risk of MetS in 567 participants (303 MetS subjects and 264 healthy controls). The baseline characteristics of the study participants are summarized in Table 1. MetS patients demonstrated a significantly higher mean age than the control subjects ( 59.0 vs. 54.7 years, $p=<0.001$ ). MetS patients had a pronounced abdominal adiposity reflected by their significantly higher waist circumference (38.2 \pm 43.9 inches in patients vs. $34.7 \pm 4.3$ inches in controls, $p=<0.001)$ and WHR $(1.0 \pm 0.1$ in patients vs. $0.93 \pm 0.06$ in controls, $p=0.000$ ). Also, significantly higher values of $\mathrm{BMI}$ and elevated blood pressure were observed in MetS patients compared to control subjects $(p<0.001)$. Following stratification of the data based on the new BMI cutoffs by the WHO Expert Consultation (2004), we observed
10

Int J Diabetes Metab 2018;24:8-15 DOI: $10.1159 / 000492478$
Bhatti/Kaur/Vijayvergiya/Bhadada/ Mastana/Singh/Bhatti 
Table 2. Biochemical parameters in the MetS and control subjects stratified by sex and disease status

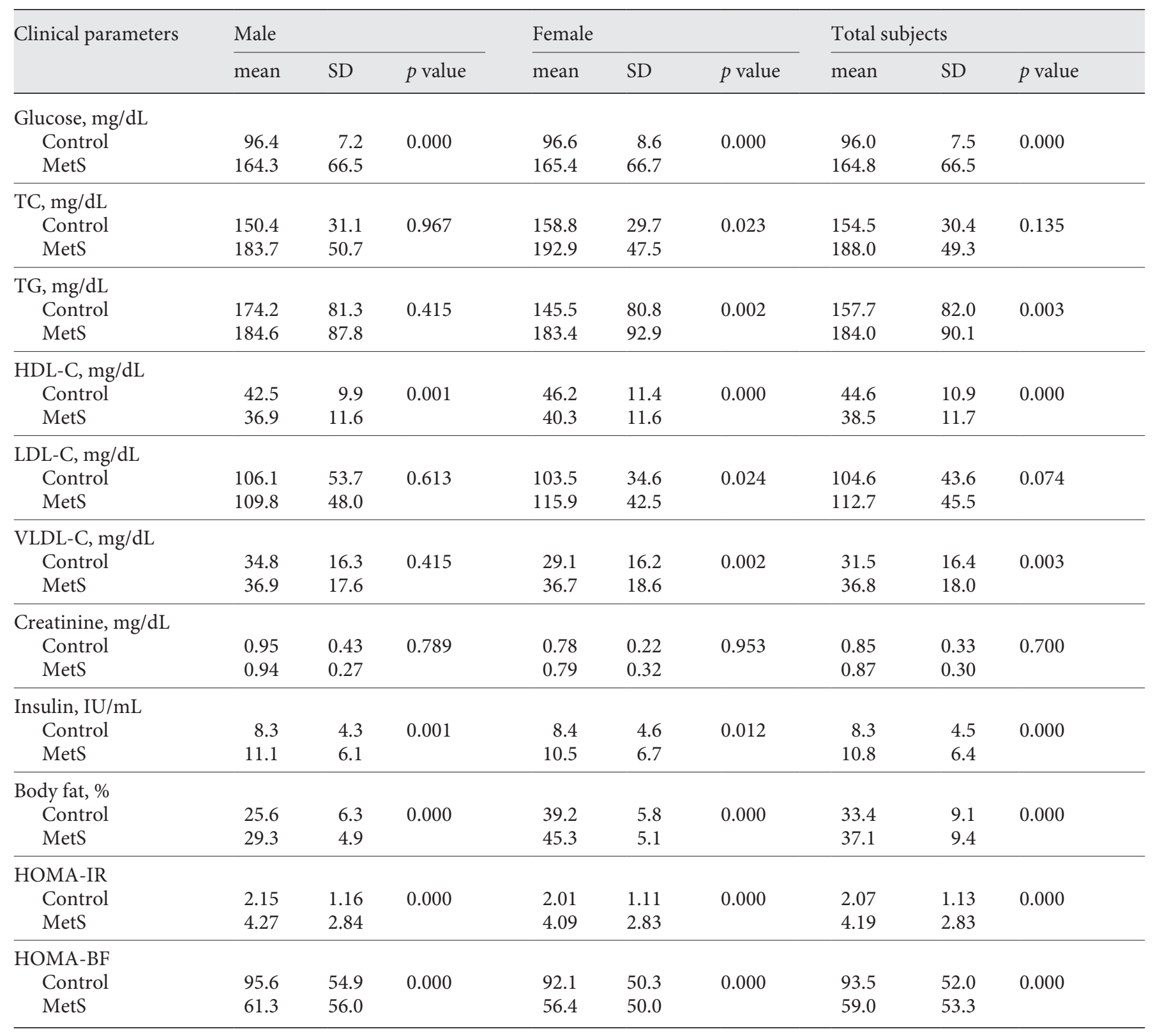

$p$ values $<0.05$ (two-tailed) were considered significantly different between MetS and controls. MetS, metabolic syndrome; SD, standard deviation; TC, total cholesterol; TG, triglycerides; HDL-C, high-density lipoprotein cholesterol; LDL-C, low-density lipoprotein cholesterol; VLDL-C, very-low-density lipoprotein cholesterol; HOMA-IR, Homeostasis Model Assessment of insulin resistance; HOMA-BF, Homeostasis Model Assessment of beta-cell function.

pronounced central obesity in both patients and controls, even at the lowest BMI values $(<23)$.

Table 2 shows the clinical characteristics of MetS patients and healthy subjects stratified by sex and disease status. MetS subjects exhibited significantly higher values of fasting glucose $(164.8 \pm 66.5$ vs. $96 \pm 7.5 \mathrm{mg} / \mathrm{dL}, p<$
0.001); TG (184 \pm 90.1 vs. $157.7 \pm 82.0 \mathrm{mg} / \mathrm{dL}, p<0.001)$; glycosylated hemoglobin $(8.2 \pm 2.4$ vs. $6.8 \pm 2.0 \%$, $p<$ $0.001)$; and insulin $(10.8 \pm 6.4$ vs. $8.3 \pm 4.5 \mathrm{IU} / \mathrm{mL}, p<$ $0.001)$ as well as reduced HDL-C (38.5 \pm 11.7 vs. $44.6 \pm$ $10.9 \mathrm{mg} / \mathrm{dL}, p<0.001)$ compared to control subjects. MetS patients demonstrated insulin resistance and beta- 
Table 3. Distribution of genotypes and allelic frequencies of ENPP1 K121Q variant in MetS and control subjects

\begin{tabular}{lllll}
\hline & $\begin{array}{l}\text { Controls, } \\
n(\%)\end{array}$ & $\begin{array}{l}\text { MetS subjects, } \\
n(\%)\end{array}$ & Test of association & \\
\cline { 4 - 4 } & & & & \\
\hline Genotypes & & & \\
KK & $161(61.0)$ & $178(58.7)$ & reference & \\
KQ & $99(37.5)$ & $118(38.9)$ & $1.078(0.766-1.517)$ & 0.666 \\
QQ & $4(1.5)$ & $7(2.3)$ & $1.583(0.455-5.507)$ & 0.470 \\
KQ+QQ & $103(39.0)$ & $125(41.3)$ & $1.097(0.784-1.540)$ & 0.587 \\
\hline Total genotypes & 264 & 303 & & \\
\hline Allele frequencies & $421(0.80)$ & $474(0.78)$ & reference & \\
K & $107(0.20)$ & $132(0.22)$ & $1.072(0.801-1.435)$ & 0.639 \\
Q & 528 & & \\
\hline Total alleles & 606 & \\
\hline \multicolumn{4}{c}{ MetS, metabolic syndrome; OR, odds ratio; CI, confidence interval. } \\
\hline
\end{tabular}

cell dysfunction evidenced by increased values of HOMAIR and decreased values of HOMA-BF, respectively, in both sexes compared to control subjects. Also, significantly high BF\% was observed in MetS patients compared to healthy control subjects $(p<0.001)$. Nevertheless, no significant differences were observed in TC, LDL-C, and creatinine levels of MetS patients compared to control subjects (Table 2).

\section{K121Q Polymorphism in ENPP1 Gene and Risk of MetS}

The distribution of genotypes and allele frequencies of the K121Q polymorphism of the ENPP1 gene are given in Table 3. The distribution of KK genotype was slightly higher in control subjects than in MetS patients (61 vs. $58.7 \%$ ). Subjects with MetS were found to have a slightly higher frequency of KQ and QQ genotypes than control subjects. Very few subjects with QQ genotypes were observed, so we also merged KQ and QQ genotypes to test for an association of the K121Q polymorphism in ENPP1 gene with the risk of MetS. The frequency of the $\mathrm{K}$ allele was similar in MetS cases and control subjects $(p=0.639)$.

Logistic regression analysis of data demonstrated a nonsignificant association of QQ and KQ+QQ genotypes with increased risk of MetS (OR [95\% CI], 1.583 [0.4555.507], $p=0.470$ for QQ genotypes and 1.097 [0.784$1.540], p=0.587$ for KQ+QQ genotypes, respectively). In order to evaluate the correlation of the K121Q polymorphism of the ENPP1 gene with metabolic traits, various clinical parameters were analyzed in all participants with
$\mathrm{KK}$ and KQ/QQ genotypes (Table 4). The results showed that MetS subjects carrying KQ+QQ genotypes had significantly higher levels of TG (174 vs. $199 \mathrm{mg} / \mathrm{dL}, p=$ $0.032)$ and VLDL-C (34.9 vs. $39.8 \mathrm{mg} / \mathrm{dL}, p=0.032)$ than those carrying KK genotypes. We further evaluated the distribution of the K121Q polymorphism in MetS patients and healthy controls. MetS subjects carrying QQ genotypes showed significantly higher values of HOMA-IR $(13.5 \pm 1.75)$ compared to those carrying KK $(4.0 \pm 2.23)$ and KQ genotypes $(3.7 \pm 2.4)$. Moreover, MetS subjects carrying Q alleles had significantly higher levels of TG, insulin, and $\mathrm{BF} \%$ than healthy controls. Nevertheless, no significant correlations were observed between the genotypes of the ENPP1 K121Q variant and other metabolic traits in MetS patients or control subjects (Table 4).

\section{Discussion}

The incidence and prevalence of MetS is rising globally. The situation of MetS in India has reached an epidemic scale. The findings of previous studies provide evidence for the escalation of MetS and its determinants [5, 19-21]. It has been reported that ENPP1 gene modulates insulin signaling by inhibiting the insulin receptor's tyrosine kinase activity and confers insulin resistance [22]. Further, this effect is modified by the K121Q polymorphism of ENPP1 gene [12]. The consistency of the prediction of the effect of the ENPP1 K121Q allele on type 2 diabetes supports the view that the ENPP1 K121Q allele is the functional variant that affects the phenotype per se $[11,23]$. During the last
12

Int J Diabetes Metab 2018;24:8-15 DOI: $10.1159 / 000492478$
Bhatti/Kaur/Vijayvergiya/Bhadada/ Mastana/Singh/Bhatti 
Table 4. Correlation of ENPP1 K121Q genotypes with measures of quantitative traits in MetS and control subjects

\begin{tabular}{|c|c|c|c|c|c|c|c|c|c|c|c|c|c|}
\hline $\begin{array}{l}\text { Characteristics/ } \\
\text { genotypes }\end{array}$ & mean & SD & $\begin{array}{l}p \\
\text { value }\end{array}$ & mean & SD & $\begin{array}{l}p \\
\text { value }\end{array}$ & $\begin{array}{l}\text { Characteristics/ } \\
\text { genotypes }\end{array}$ & mean & SD & $\begin{array}{l}p \\
\text { value }\end{array}$ & mean & SD & $\begin{array}{l}p \\
\text { value }\end{array}$ \\
\hline \multicolumn{7}{|l|}{ Age, years } & \multicolumn{7}{|l|}{$\mathrm{TG}, \mathrm{mg} / \mathrm{dL}$} \\
\hline $\mathrm{KK}$ & 55.3 & 14.1 & 0.405 & 58.5 & 10.1 & 0.314 & KK & 153.1 & 82.5 & 0.424 & 174.3 & 83.4 & 0.032 \\
\hline KQ+QQ & 53.8 & 14.6 & & 59.7 & 10.8 & & KQ+QQ & 163.6 & 81.7 & & 199.0 & 97.9 & \\
\hline KQ+QQ & 26.6 & 4.1 & & 28.2 & 4.3 & & KQ+QQ & 41.7 & 10.2 & & 39.2 & 11.6 & \\
\hline \multicolumn{7}{|l|}{$\mathrm{WC}$, inch } & \multicolumn{7}{|l|}{ LDL-C, $\mathrm{mg} / \mathrm{dL}$} \\
\hline KK & 34.6 & 4.4 & 0.569 & 38.4 & 3.8 & 0.300 & $\mathrm{KK}$ & 105.3 & 48.0 & 0.807 & 112.4 & 46.6 & 0.900 \\
\hline KQ+QQ & 34.9 & 4.3 & & 38.0 & 4.1 & & KQ+QQ & 103.6 & 37.4 & & 113.1 & 44.1 & \\
\hline \multicolumn{7}{|l|}{$\mathrm{HC}$, inch } & \multicolumn{7}{|l|}{ VLDL-C, mg/dL } \\
\hline KQ+QQ & 0.94 & 0.08 & & 0.97 & 0.06 & & KQ+QQ & 0.84 & 0.25 & & 0.85 & 0.32 & \\
\hline \multicolumn{7}{|c|}{ Systolic BP, mm Hg } & \multicolumn{7}{|l|}{ Insulin, IU/mL } \\
\hline $\mathrm{KK}$ & 139.51 & 26.29 & 0.052 & 149.15 & 21.65 & 0.432 & KK & 8.5 & 4.7 & 0.680 & 9.50 & 6.5 & 0.008 \\
\hline KQ+QQ & 133.20 & 24.50 & & 151.22 & 23.98 & & KQ+QQ & 8.2 & 4.2 & & 11.6 & 6.0 & \\
\hline \multicolumn{7}{|c|}{ Diastolic BP, mm Hg } & \multicolumn{7}{|l|}{ Body fat, \% } \\
\hline KK & 83.17 & 13.49 & 0.021 & 86.96 & 12.28 & 0.576 & KK & 33.8 & 8.9 & 0.425 & 36.2 & 8.9 & 0.042 \\
\hline KQ+QQ & 79.44 & 11.39 & & 86.15 & 12.27 & & KQ+QQ & 32.8 & 9.4 & & 39.3 & 10.0 & \\
\hline \multicolumn{7}{|l|}{ Glucose, mg/dL } & \multicolumn{7}{|l|}{ HOMA-IR } \\
\hline $\mathrm{KK}$ & 96.1 & 7.8 & 0.699 & 166.1 & 67.6 & 0.682 & KK & 2.10 & 1.19 & 0.746 & 2.93 & 2.98 & 30.020 \\
\hline KQ+QQ & 95.7 & 7.0 & & 163.0 & 65.0 & & KQ+QQ & 2.03 & 1.04 & & 3.65 & 2.50 & \\
\hline \multicolumn{7}{|l|}{$\mathrm{TC}, \mathrm{mg} / \mathrm{dL}$} & \multicolumn{7}{|l|}{ HOMA-BF } \\
\hline
\end{tabular}

$p$ values $<0.05$ (two-tailed) were considered significantly different between genotypes. MetS, metabolic syndrome; SD, standard deviation; BMI, body mass index; WC, waist circumference; HC, hip circumference; WHR, waist to hip ratio; BP, blood pressure; TC, total cholesterol; TG, triglycerides; HDL-C, high-density lipoprotein cholesterol; LDL-C, low-density lipoprotein cholesterol; VLDL-C, very-low-density lipoprotein cholesterol; HOMA-IR, Homeostasis Model Assessment of insulin resistance; HOMA-BF, Homeostasis Model Assessment of beta-cell function.

decade, genetic association studies have established a positive association between ENPP1 K121Q polymorphism and the pathophysiology of insulin resistance or type 2 diabetes [24-30], obesity [31, 32], and other MetS [30, 3336]. However, studies of the clinical impact of the K121Q polymorphism have generated conflicting results.

The present study did not predict the association of the ENPP1 K121Q polymorphism with MetS and related quantitative metabolic traits in this population; however, the sample had sufficient power for detecting the association at a moderate level. Among MetS individuals carrying the KQ/QQ genotype, higher values of TG and insulin resistance reflected by HOMA-IR indicated insulin resis- tance in MetS patients. Recently, a study has demonstrated that the ENPP1 gene polymorphism is associated with hypertriglyceridemia and may contribute to insulin resistance or MetS [37]. Our results are similar to those of a vast majority of studies carried out in different populations. No evidence for an association of the ENPP1 K121Q variant with insulin resistance or type 2 diabetes was reported in Japanese [38], Spanish [39], Danish Caucasian [40], North Indian [13], UK Caucasian [41], and Chinese [42] populations. Besides, a great difference in allele frequencies was observed between the different populations $[26,36,43]$. It is possible that the susceptibility induced by the ENPP1 K121Q gene polymorphism is modulated by 
interactions with other ethnicity-specific genetic or environmental factors. Previous studies in Indians and other ethnic groups demonstrated that those carrying the ENPP1 K121Q variant have an increased risk of developing type 2 diabetes and cardiovascular diseases [25, 28, 44, 45]. The same genetic determinants might have a different contribution to the etiology of a complex disease when interacting with different environmental factors. ENPP1 K121Q may contribute to the determination of an ethnic susceptibility to insulin resistance and type 2 diabetes. However, the present data demonstrated the association of the ENPP1 K121Q polymorphism with insulin resistance measured by HOMA-IR, and our results are in line with various studies carried out in other parts of the world $[12,22,24,31]$. We did not find any association with other metabolic quantitative traits, such as BMI, WHR and TC, LDL-C, and insulin levels. However, the K121Q polymorphism may be associated with insulin resistance and dyslipidemia reflected by low HDL and hypertriglyceridemia in MetS subjects. The reason for the apparent discrepancies between studies, including ours, which have evaluated the pathogenic impact of the K121Q variant, is far from obvious. It is possible that the susceptibility induced by the polymorphism is modulated by interactions with other ethnicity-specific genetic or environmental factors and that the phenotypic expression of the variant will, therefore, be different in various ethnic populations. In this regard, it is emphasized that the frequency of the K121Q polymorphism varies considerably between different ethnic groups. Further, large studies are necessary to ascertain the validity of the described genotype-phenotype relationship in an Asian Indian population. In conclusion, our data suggest that the ENPP1 K121Q polymorphism may be associated with insulin resistance and dyslipidemia in MetS subjects of a north Indian population.

\section{Acknowledgment}

We are very thankful to the University Grant Commission for providing financial assistance to carry out the present study. We would also like to thank all the volunteers and participants who rendered repeated help and cooperation during the recruitment of the study subjects.

\section{Statement of Ethics}

The study was ethically cleared by the Institutional Ethics Committee of Postgraduate Institute of Medical Education and Research, Chandigarh, India.

\section{Disclosure Statement}

The authors have no conflicts of interest to declare.

\section{Funding Sources}

University Grant Commission, Government of India.

\section{Author Contributions}

G.K.B.: planning, data collection, and manuscript writing. S.K.: patient recruitment and data collection. S.K.B.: patient recruitment and data collection. R.V.: patient recruitment and data collection. S.S.M.: performed statistical analysis of the data. B.S.: conceived and designed the data analysis. J.S.B.: conceiving, planning, and implication of the project; data collection, manuscript writing, and submission.

\section{References}

1 Misra A, Khurana L: The metabolic syndrome in South Asians: epidemiology, determinants, and prevention. Metab Syndr Relat Disord 2009;7:497-514.

2 Guariguata L, Whiting DR, Hambleton I, Beagley J, Linnenkamp U, Shaw JE: Global estimates of diabetes prevalence for 2013 and projections for 2035. Diabetes Res Clin Pract 2014;103:137-149.

3 Pandit K, Goswami S, Ghosh S, Mukhopadhyay P, Chowdhury S: Metabolic syndrome in South Asians. Indian J Endocrinol Metab 2012;16:44-55.
4 Misra A, Misra R, Wijesuriya M, Banerjee D: The metabolic syndrome in South Asians: continuing escalation and possible solutions. Indian J Med Res 2007;125:345-354.

5 Bhatti GK, Bhadada SK, Vijayvergiya R, Mastana SS, Bhatti JS: Metabolic syndrome and risk of major coronary events among the urban diabetic patients: North Indian Diabetes and Cardiovascular Disease Study-NIDCVD-2. J Diabetes Complications 2016;30: 72-78.
6 Isomaa B, Almgren P, Tuomi T, Forsen B, Lahti K, Nissen M, et al: Cardiovascular morbidity and mortality associated with the metabolic syndrome. Diabetes Care 2001;24:683689.

7 Obunai K, Jani S, Dangas GD: Cardiovascular morbidity and mortality of the metabolic syndrome. Med Clin North Am 2007;91:11691184, $\mathrm{x}$.

8 Das M, Pal S, Ghosh A: Association of metabolic syndrome with obesity measures, metabolic profiles, and intake of dietary fatty acids in people of Asian Indian origin. J Cardiovasc Dis Res 2010;1:130-135. 
9 Lin HF, Boden-Albala B, Juo SH, Park N, Rundek T, Sacco RL: Heritabilities of the metabolic syndrome and its components in the Northern Manhattan Family Study. Diabetologia 2005;48:2006-2012.

10 Prudente S, Morini E, Trischitta V: Insulin signaling regulating genes: effect on T2DM and cardiovascular risk. Nat Rev Endocrinol 2009;5:682-693.

11 Maddux BA, Goldfine ID: Membrane glycoprotein PC-1 inhibition of insulin receptor function occurs via direct interaction with the receptor alpha-subunit. Diabetes 2000;49:1319.

12 Costanzo BV, Trischitta V, Di Paola R, Spampinato D, Pizzuti A, Vigneri R, et al: The Q allele variant (GLN121) of membrane glycoprotein PC-1 interacts with the insulin receptor and inhibits insulin signaling more effectively than the common $\mathrm{K}$ allele variant (LYS121). Diabetes 2001;50:831-836.

13 Bhatti J, Bhatti G, Mastana S, Ralhan S, Joshi A, Tewari R: ENPP1/PC-1 K121Q polymorphism and genetic susceptibility to type 2 diabetes in North Indians. Mol Cell Biochem 2010;345:249-257.

14 Bhatti G, Puar S, Saini N, Bhadada S, Vijayvergiya $R$, Mastana $S$, et al: Evaluation of risk factors associated with type 2 diabetes and related complications in Asian Indians: the North Indian Diabetes and Cardiovascular Disease (NIDCVD) Study-I. J Diabetes Metab 2014, DOI: 10.4172/2155-6156.1000462.

15 Misra A, Wasir JS, Pandey RM: An evaluation of candidate definitions of the metabolic syndrome in adult Asian Indians. Diabetes Care 2005;28:398-403.

16 Lean ME, Han TS, Bush H, Anderson AS, Bradby H, Williams R: Ethnic differences in anthropometric and lifestyle measures related to coronary heart disease risk between South Asian, Italian and general-population British women living in the west of Scotland. Int J Obes Relat Metab Disord 2001;25:1800-1805.

17 Matthews DR, Hosker JP, Rudenski AS, Naylor BA, Treacher DF, Turner RC: Homeostasis model assessment: insulin resistance and beta-cell function from fasting plasma glucose and insulin concentrations in man. Diabetologia 1985;28:412-419.

18 Snehalatha C, Viswanathan V, Ramachandran A: Cutoff values for normal anthropometric variables in Asian Indian adults. Diabetes Care 2003;26:1380-1384.

19 Stancakova A, Laakso M: Genetics of metabolic syndrome. Rev Endocr Metab Disord 2014, DOI: 10.1007/s11154-014-9293-9.

20 Manjunath D, Uthappa CK, Kattula SR, Allam RR, Chava N, Oruganti G: Metabolic syndrome among urban Indian young adults: prevalence and associated risk factors. Metab Syndr Relat Disord 2014;12:381-389.

21 Balasubramanyam A, Rao S, Misra R, Sekhar RV, Ballantyne CM: Prevalence of metabolic syndrome and associated risk factors in Asian Indians. J Immigr Minor Health 2008; 10: 313-323.
22 Pizzuti A, Frittitta L, Argiolas A, Baratta R, Goldfine ID, Bozzali M, et al: A polymorphism (K121Q) of the human glycoprotein PC-1 gene coding region is strongly associated with insulin resistance. Diabetes 1999;48: 1881-1884.

23 Frittitta L, Camastra S, Baratta R, Costanzo BV, D'Adamo M, Graci S, et al: A soluble PC-1 circulates in human plasma: relationship with insulin resistance and associated abnormalities. J Clin Endocrinol Metab 1999; 84:3620-3625.

24 Gu HF, Almgren P, Lindholm E, Frittitta L, Pizzuti A, Trischitta V, et al: Association between the human glycoprotein PC-1 gene and elevated glucose and insulin levels in a pairedsibling analysis. Diabetes 2000;49:1601-1603.

25 Abate N, Chandalia M, Satija P, Adams-Huet B, Grundy SM, Sandeep S, et al: ENPP1/PC-1 K121Q polymorphism and genetic susceptibility to type 2 diabetes. Diabetes 2005;54: 1207-1213.

26 Hamaguchi K, Terao H, Kusuda Y, Yamashita T, Hazoury Bahles JA, Cruz LM, et al: The PC-1 Q121 allele is exceptionally prevalent in the Dominican Republic and is associated with type 2 diabetes. J Clin Endocrinol Metab 2004;89:1359-1364.

27 Abate N, Carulli L, Cabo-Chan A Jr, Chandalia M, Snell PG, Grundy SM: Genetic polymorphism PC-1 K121Q and ethnic susceptibility to insulin resistance. J Clin Endocrinol Metab 2003;88:5927-5934

28 Bacci S, Ludovico O, Prudente S, Zhang YY, Di Paola R, Mangiacotti D, et al: The K121Q polymorphism of the ENPP1/PC-1 gene is associated with insulin resistance/atherogenic phenotypes, including earlier onset of type 2 diabetes and myocardial infarction. Diabetes 2005;54:3021-3025.

29 Badaruddoza BB, Matharoo K, Bhanwer AJS: Role of the ENPP1 K121Q polymorphism and susceptibility to type 2 diabetes in North Indian Punjabi population. J Diabetes Metab Disord 2014;5:450.

30 Prakash J, Mittal B, Awasthi S, Agarwal CG, Srivastava N: K121Q ENPP1/PC-1 gene polymorphism is associated with insulin resistance in a North Indian population. J Genet 2013;92:571-576.

31 Frittitta L, Baratta R, Spampinato D, Di Paola R, Pizzuti A, Vigneri R, et al: The Q121 PC-1 variant and obesity have additive and independent effects in causing insulin resistance. J Clin Endocrinol Metab 2001;86:5888-5891.

32 RuoQi W, DongHao Z, Bo X, XiuShan G, Ping Z, Bo W, et al: ENPP1/PC-1 gene K121Q polymorphism is associated with obesity in European adult populations: evidence from a meta-analysis involving 24,324 subjects. Biomed Environ Sci 2011:24:200-296.

33 Li N, Pan H, Cui M, Li Q: Association of K121Q polymorphism in ectonucleotide pyrophosphatase/phosphodiesterase 1 with clinical characteristics of metabolic syndrom. Exp Clin Endocrinol Diabetes 2016;124:313317.
34 Hsiao TJ, Lin E: The ENPP1 K121Q polymorphism is associated with type 2 diabetes and related metabolic phenotypes in a Taiwanese population. Mol Cell Endocrinol 2016;433: 20-25.

35 Tang ST, Shen XR, Tang HQ, Wang CJ, Wei W, Zhang Q, et al: Association of the ENPP1 K121Q polymorphism with susceptibility to type 2 diabetes in different populations: evidence based on 40 studies. Endocr J 2014;61: 1093-1103.

36 Kubaszek A, Pihlajamaki J, Karhapaa P, Vauhkonen I, Laakso M: The K121Q polymorphism of the PC-1 gene is associated with insulin resistance but not with dyslipidemia. Diabetes Care 2003;26:464-467.

37 Tanyolac S, Bremer AA, Hodoglugil U, Movsesyan I, Pullinger CR, Heiner SW, et al: Genetic variants of the ENPP1/PC-1 gene are associated with hypertriglyceridemia in male subjects. Metab Syndr Relat Disord 2009;7: 543-548.

38 Keshavarz P, Inoue H, Sakamoto Y, Kunika K, Tanahashi T, Nakamura N, et al: No evidence for association of the ENPP1 (PC-1) K121Q variant with risk of type 2 diabetes in a Japanese population. J Hum Genet 2006;51:559566.

39 Gonzalez-Sanchez JL, Martinez-Larrad MT, Fernandez-Perez C, Kubaszek A, Laakso M, Serrano-Rios M: K121Q PC-1 gene polymorphism is not associated with insulin resistance in a Spanish population. Obes Res 2003;11: 603-605.

40 Rasmussen SK, Urhammer SA, Pizzuti A, Echwald SM, Ekstrom CT, Hansen L, et al: The K121Q variant of the human PC-1 gene is not associated with insulin resistance or type 2 diabetes among Danish Caucasians. Diabetes 2000;49:1608-1611.

41 Weedon MN, Shields B, Hitman G, Walker M, McCarthy MI, Hattersley AT, et al: No evidence of association of ENPP1 variants with type 2 diabetes or obesity in a study of 8,089 U.K. Caucasians. Diabetes 2006;55:31753179.

42 Zhao T, Liu Z, Zhang D, Liu Y, Yang Y, Zhou $\mathrm{D}$, et al: The ENPP1 K121Q polymorphism is not associated with type 2 diabetes or obesity in the Chinese Han population. J Hum Genet 2011;56:12-16.

43 Matsuoka N, Patki A, Tiwari HK, Allison DB, Johnson SB, Gregersen PK, et al: Association of K121Q polymorphism in ENPP1 (PC-1) with BMI in Caucasian and African-American adults. Int J Obes 2006;30:233-237.

44 Sumi S, Ramachandran S, RamanKutty V, Patel MM, Anand T, Mullasari AS, et al: ENPP1 121Q functional variant enhances susceptibility to coronary artery disease in South Indian patients with type 2 diabetes mellitus. Mol Cell Biochem 2017;435:67-72.

45 Ali S, Chopra R, Manvati S, Singh YP, Kaul N, Behura A, et al: Replication of type 2 diabetes candidate genes variations in three geographically unrelated Indian population groups. PLoS One 2013;8:e58881.
ENPP1 K121Q Variant in Metabolic Syndrome in Asian Indians
Int J Diabetes Metab 2018;24:8-15 DOI: $10.1159 / 000492478$ 